Portland State University

PDXScholar

1987

\title{
Isolating factors predicting cooperation in work groups : leader motivation and style
}

Denise Hunter Velaski

Portland State University

Follow this and additional works at: https://pdxscholar.library.pdx.edu/open_access_etds

Part of the Psychology Commons, and the Work, Economy and Organizations Commons Let us know how access to this document benefits you.

\section{Recommended Citation}

Velaski, Denise Hunter, "Isolating factors predicting cooperation in work groups : leader motivation and style" (1987). Dissertations and Theses. Paper 3760.

https://doi.org/10.15760/etd.5645

This Thesis is brought to you for free and open access. It has been accepted for inclusion in Dissertations and Theses by an authorized administrator of PDXScholar. Please contact us if we can make this document more accessible: pdxscholar@pdx.edu. 
AN ABSTRACT OF THE THESIS OF Denise Hunter Velaski for the Master of Science in Psychology presented February 9, 1987. Title: Isolating Factors Predicting Cooperation in work Groups: Leader Motivation and Style

APPROVED BY MEMBERS OF THE THESIS COMMITTEE:

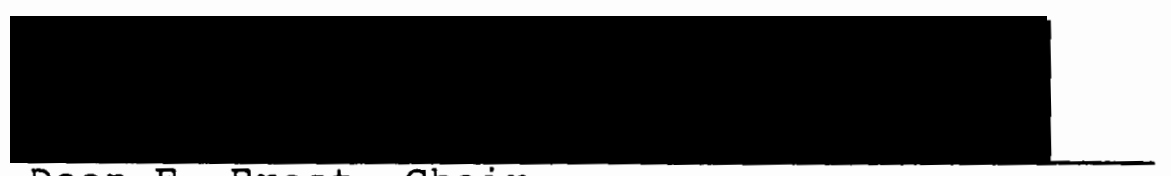

Dean E. Frost, Chair

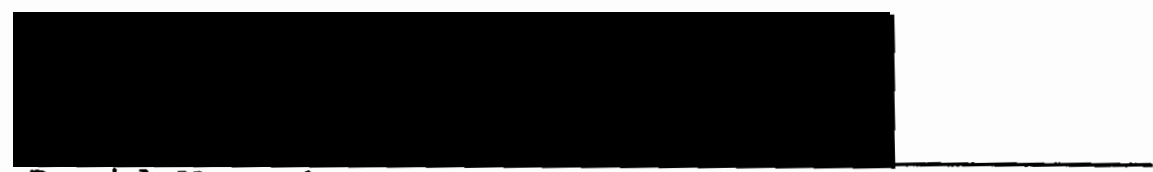

$$
\text { David Wrench }
$$

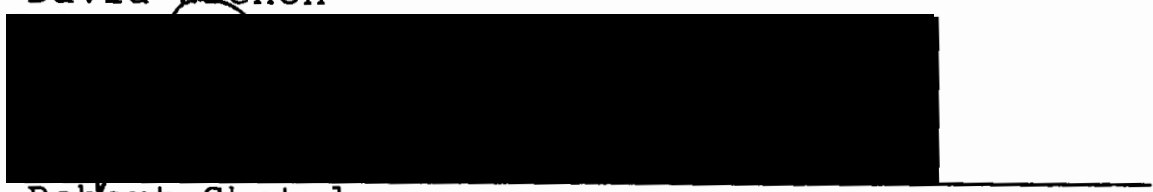

Robert Shotola

There is evidence that cooperation in the workplace can have positive outcomes for organizations. To take advantage of these outcomes, it would be useful to gain information about the causes of cooperation. This study attempts to isolate some factors, leader motivation and style in particular, that may predict cooperation within work groups.

Members of existing work groups in an electronics manufacturing organization participated by completing a questionnaire comprised of items from: the Leader Member 
Relations Scale (Fiedler, 1978); the Manifest Needs Questionnaire (Steers \& Braunstein, 1976); the Leader Behavior Description Questionnaire (Stodgill, 1974); and a modified version of Tjsovold's Cooperation Scale (1984). The analysis demonstrates that groups with high Dominance-motivated leaders report less intragroup cooperation. This effect is explained in terms of Path-Goal Theory (House \& Mitchell, 1971) and Deutsch's (1949) Theory of Cooperation. The relationships between cooperation and the remaining three motivations, Affiliation, Achievement, and Autonomy cannot be reported with confidence due to the poor reliability of these three subscales. Group cooperation was shown to correlate significantly with group atmosphere, leader communication behavior, and satisfaction with group performance. The implications of this study and suggestions for future research are offered. 
ISOLATING FACTORS PREDICTING COOPERATION IN WORK GROUPS:

LEADER MOTIVATION AND STYLE

by

DENISE HUNTER VELASKI

A thesis submitted in partial fulfillment of the requirements for the degree of

MASTER OF SCIENCE

in

PSYCHOLOGY

Portland State University

1987 
TO THE OFFICE OF GRADUATE STUDIES AND RESEARCH:

The members of the Committee approve the thesis of Denise Hunter Velaski presented February 9, 1987.
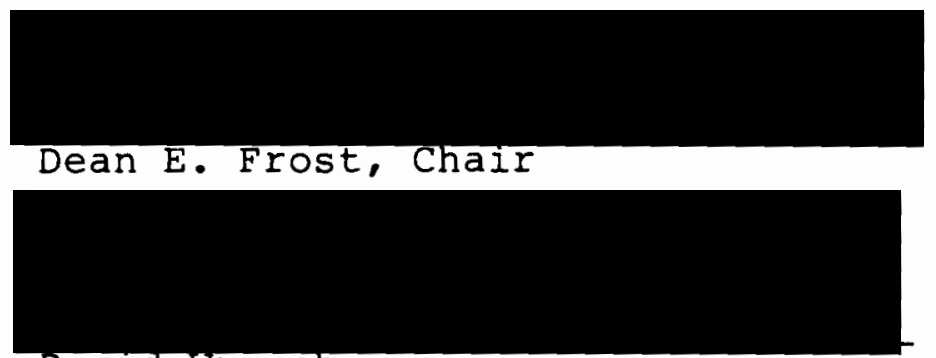

David wrench

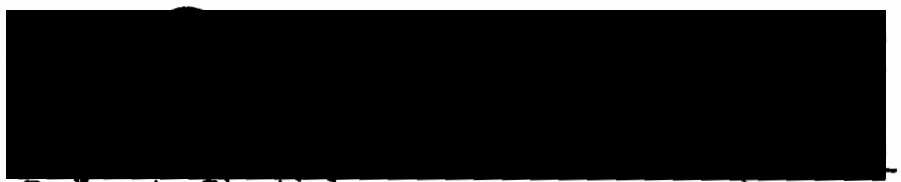

Robert Shotola

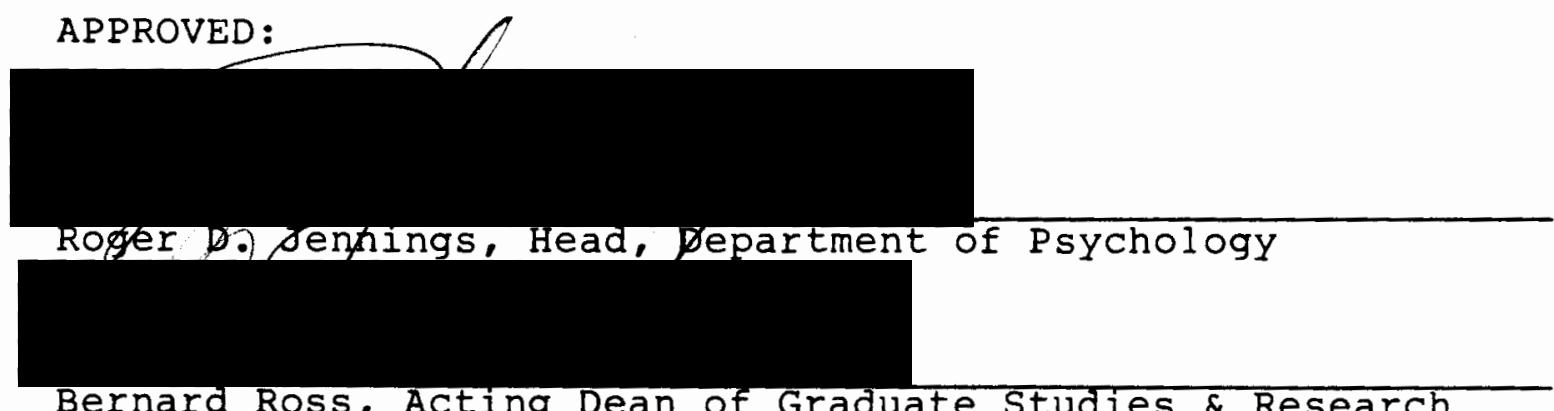

Bernard Ross, Acting Dean of Graduate Studies \& Research 


\section{ACKNOWLEDGEMENTS}

I am deeply grateful for the generosity of Tektronix, Inc., and particularly Janice Druian, for granting me access to the organization. The willingness of the employees to take part in this project made it all possible.

A special thanks goes out to Dr. Dean Frost for his unfailing ability to provide me with creative ideas, encouragement, and above all, motivation. This project is as much his as it is mine. The comments and ideas of Dr. David Wrench and Dr. Robert Shotola enabled me to look at this project from various points of view and thus improve its quality. Their efforts are greatly appreciated.

This project would not have been undertaken without a "push" given to me by Dr. Ray stinnett. I will always be grateful for that push.

Finally, this project is dedicated to Brian Velaski for his unconditional love and support. 
TABLE OF CONTENTS

PAGE

ACKNOWLEDGEMENTS . . . . . . . . . . . . . . iii

LIST OF TABLES . . . . . . . . . . . . • . • • • • v

CHAPTER

I INTRODUCTION . . . . . . . . . . 1

Cooperation ........... . . 2

Leader Motive Style... . . . . 8

Hypotheses . . . . . . . . . 10

II METHOD . . . . . . . . . . . . 13

Subjects ............. . 14

Instrument . . . . . . . . 15

Procedure ............ 18

II RESULTS . . . . . . . . . . . 20

Reliability of Measures... . . . 20

Test of Hypotheses . . . . . . . 24

IV DISCUSSION . . . . . . . . . . . 29

REFERENCES . . . . . . . . . . . . . . 41

APPENDIX . . . . . . . . . . . . . . . 4 46 


\section{LIST OF TABLES}

TABLE

PAGE

I Cooperation Scale Characteristics . . . 20

I Leader Behavior Description Questionnaire Subscale Characteristics . . . . . 21

II Leader Member Relations Scale Characteristics 22

IV Manifest Needs Questionnaire Scale

Characteristics.......... . 23

V Group Members' Perceptions of Cooperation

and Competition When Group Leaders' Motives are Compared . . . . . . . . . . . .

VI Significant Differences in Cooperation and

Competition Between Groups Led by

Individuals of High and Low Need for

Dominance . . . . . . . . . . .

VII Correlation Coefficients for Satisfaction

and Reports of Group Atmosphere,

Cooperation, and Leader Behavior . . . 28 
CHAPTER I

\section{INTRODUCTION}

The topic of cooperation and competition has long been a concern of researchers interested in both group and individual behavior. The bulk of the research in this area has taken place in educational settings and investigates the effects of cooperative and competitive goal structures on students (Johnson \& Johnson, 1974). During the past thirtyfive years, since the development of the Theory of Cooperation and Competition by Deutsch (1949a), relatively little research has applied this theory to the workplace. In recent years, however, there has been a renewed interest in how cooperation and competition affect aspects of work. The proposed study attempts to address the issue of cooperation in the workplace by focusing on the individual who is most important in determining cooperation in work groups, the leader. Reports of cooperation in work groups and important facts about leaders, particularly their motives and style, will be examined. Before addressing the relevance of leader motive style to cooperation, a summary of Deutsch's theory and a brief literature review will be presented. 


\section{COOPERATION}

Deutsch (1949a) developed a theory of cooperation and competition that serves as an explanation of the processes as well as the outcomes of cooperation and competition. Cooperation is defined as a situation in which the goals of individuals are interdependent in such a way that there is a positive relationship between the goal attainment of individuals. Movement toward one's goal facilitates goal attainment for all involved.

Competition is defined as a situation in which the goals of individuals are interdependent in such a way that there is a negative relationship between the goal attainment of individuals. Movement toward one's goal hinders the goal attainment of others. The critical aspect of each of these situations is goal interdependence; without it neither cooperation or competition exists.

Deutsch $(1949 \mathrm{~b})$ developed and tested a number of predictions about the outcomes of cooperation and competition that Tjsovold (1984) grouped into four categories:

- Expected and Actual Assistance: In cooperation, individuals expect and give one another assistance. In competition, individuals distrust others and refuse to assist, as well as refuse to accept assistance from others. In some cases, they may 
attempt to obstruct the progress of others.

- Communication and Influence: Cooperation will

facilitate accurate communication among individuals, and individuals will be more open to the influence of others. In competition individuals are reluctant to share information and suspect the information and influence of others.

- Task orientation: Individuals in cooperation will divide labor to reach their goal most efficiently. Competitors must each complete every aspect of the task individually and may try to obstruct the performance of others.

- Friendliness and Support: In cooperation, each member's contribution to goal attainment is valued as effective behavior by others. This may generalize into positive attitudes toward each other. In competition, the limited availability of goal attainment may lead to frustration and dislike of those who are seen as interfering with one's goal.

Deutsch's study (1949b) to test these predictions provides support for the theory and interesting results. In cooperative group settings, members rated fellow group members more favorably, reported the task as more enjoyable, exhibited less hostility, demonstrated greater motivation, 
divided labor more often, influenced one another more successfully, attained their goals faster, and were more group- (rather than individually-) oriented than members of competitive groups.

The outcomes of expected and actual assistance, communication and influence, task orientation, and friendliness and support in the cooperation condition are all positive outcomes in an organizational setting. The goals of individuals and departments in an organization are all in some way interdependent. Thus, the work environment may be either competitive or cooperative. Deutsch's results indicate that the cooperative environment would result in more positive outcomes than the competitive environment. There are three reviews of the cooperation and competition research (Deutsch, 1980; Johnson \& Johnson, 1974; and Tjsovold, 1984) that provide excellent summaries of the work in this area. The bulk of the work supports Deutsch's theory.

There has been debate over the effectiveness of cooperation and competition in increasing productivity. This is of particular interest to organizations because productivity has direct implications on profit and organizational effectiveness. Johnson et al. (1981) have conducted a meta-analysis of over one hundred studies on productivity and goal interdependent situations. The 
results of individual studies were mixed, but in the metaanalysis it was shown that cooperation and competition result in minute differences in productivity measures on most tasks. Overall, cooperation resulted in slightly higher productivity. Competition was superior in simple tasks such as correction, adding numbers, and reaction time. Tasks such as these and timed tasks may be enhanced by increased arousal resulting from competition (scott \& Cherrington, 1974).

Cooperative situations have been shown to promote social interaction (Dunn \& Goldman, 1966; Johnson, D. W. \& Johnson, S., 1972; Johnson, S. \& Johnson, D. W., 1972; Tjsovold, 1981) and to facilitate the seeking and giving of information about the group's tasks (Jones \& Vroom, 1964); Zander \& Wolfe, 1964). Jones \& Vroom (1964) also reported an increase in the division of labor and better performance in cooperative groups.

Cooperative situations that result in mutual goal facilitation have been well documented. Several studies report that positive attitudes about the helping behavior of an individual generalizes to a positive attitude toward that individual (Blau, 1954; Deutsch, 1949a; Dunn \& Goldman, 1966; Jones \& Vroom, 1964; Raven \& Eachus, 1963). Jones and Vroom (1964) state that "persons in a cooperative relation are more satisfied with the task and interpersonal relations 
than persons in competitive relations." These same studies that report cooperative relationships as being friendly also report competitive relationships with mutual goal frustration as leading to aggression, hostility, suspicion, obstruction, and inability to share information.

Within task performing groups, cooperation has been shown to result in better group problem solving (Deutsch, 1949b; Jones \& Vroom, 1964). The increased information exchange and willingness to be influenced among cooperators allows for the best decision to surface and increases the chance that it will be adopted.

The literature overwhelmingly supports the use of cooperation to enhance positive social interaction and productivity. There are, however, some limiting factors to cooperation. The type of task dictates whether or not cooperation is useful; a simple task that requires only one person to complete will not benefit from cooperation--only tasks that require a coordination of efforts can be enhanced by cooperation. It is also important that there be an opportunity for individuals to interact and that channels of communication be available.

A possible negative effect of cooperation in groups is the social loafing effect. Latane (1979) found that as the number of people in a group increases, the effort of each individual decreases. If this effect holds true, 
cooperating groups will not perform to the best of their abilities. In groups wherein each member is working on the same task to complete the work or achieve the goal, social loafing is likely to occur. In these situations competition may change the perspective from "working with" to "working against," thus decreasing social loafing and perhaps increasing productivity. Harkins \& Petty (1982) found that social loafing effect does not occur in groups if the members believe that their individual efforts make a unique contribution to the group or if each individual is responsible for a specific part of the task. Groups that depend on different members to make unique contributions or to complete specific aspects of the task are not likely to experience social loafing. These groups require a coordination of work efforts that might be accomplished through cooperation.

To summarize the above literature review: Competition can result in increased productivity and quicker response rates in simple, means-independent tasks. It may also prevent social loafing. Competition among group members has been shown to be detrimental to intragroup relations and communication. It has been associated with distrust, hostility, aggression, and an absence of information and resource sharing. Cooperation can result in equal or greater productivity than than found with competition. 
Cooperation has been associated with positive social interaction and attraction, increased satisfaction, and increased sharing of information and resources.

It may be concluded, then, that in organizational settings where coordination of efforts is required to achieve goals $(e . g .$, where work is done in departmental groups and work teams), cooperation can have positive effects. It can increase the flow of information, facilitate positive attitudes among members, promote helping behavior, and enhance productivity. These effects are valuable and should be promoted in organizations.

\section{LEADER MOTIVE STYLE}

In a review of the application of cooperation theory to organizations, Tjosvold (1984) called for research to clarify factors that lead to cooperative or competitive goal interdependence in organizations. Among the factors suggested for this type of research is leadership. Many studies, notably Lewin, Lippett \& White (1939), have established that leadership style influences the behavior and perceptions of subordinates. The purpose of the present study is to begin to isolate leadership factors that may influence cooperation within work groups. The factor to be examined is leader motivation.

There are several motives or need categories that are 
related to work behavior (MCClelland, 1961, 1965) and have some relevance to cooperation. The first is the need for affiliation. This need involves a desire for companionship and friendly interpersonal relationships. It involves working as a part of a group or team, maintaining harmonious relations and avoiding conflict. Cooperation could facilitate the type of environment that best meets the needs of an affiliation-motivated individual.

The need for achievement is characterized by a desire to perform better than others, to reach goals, and to feel challenged. Individuals with strong achievement needs prefer tasks that can be mastered through their own unique efforts. McClelland $(1961,1965)$ found that individuals with high achievement needs enjoy competition.

The need for dominance (i.e., power) is identified by a desire to influence and persuade others to change their behavior and attitudes, to be in a position of authority over others, and to control information and resources as well as people and activities (McClelland, 1965). People with a high need for dominance might be more interested in controlling information and resources than cooperatively sharing them.

Finally, a need for autonomy (independence) indicates a desire to be solely responsible for one's own activities and to be free from the control of authority. The individual 
with a high need for autonomy usually avoids relying on others for information and resources and, because the individual with a high need for autonomy strives for independence, he or she might avoid situations with interdependent goals, thus avoiding cooperation or competition.

The relationship between these motivations and cooperation and competition in work groups will be examined. The Path-Goal Theory of Leadership developed by Evans (1970) and expanded by House (1971) states that

the role of the leader is to provide subordinates with coaching, guidance, and the rewards necessary for satisfactory and effective performance. These actions are seen as ways to influence subordinates' perception of the clarity of the path to goals and the desirability of the goals themselves. (Mitchell, 1979, p. 264)

If the group leader exerts a guiding influence on the group and provides information about the way goals should be reached, his or her motivational needs may have an impact on the group's cooperative or competitive orientation toward goals.

HYPOTHESES

Path-Goal Theory (House, 1971) explains the leader's role as influencing subordinates' perception of goals and ways of attaining these goals. McClellend's $(1961,1965)$ 
theory of motive styles states that individuals have unique motive styles that influence their work behavior. In bringing together these two theories, it is possible that leaders with certain motive styles might influence their subordinates' perceptions of cooperative or competitive goal structure within work groups. This study will examine the relationship between leader motive style and subordinate perception of cooperative and competitive goal structures in work groups.

It is hypothesized that:

(1) groups with a leader whose motive profile shows high affiliation will report significantly higher group cooperation than those groups with a leader whose motive profile shows low affiliation;

(2) Groups with a leader whose motive profile shows high achievement will report significantly higher competition than those groups with a leader whose motive profile shows low achievement;

(3) groups with a leader whose motive profile shows high autonomy will report significantly lower cooperation than those groups with a leader whose motive profile shows low autonomy; 
(4) groups with a leader whose motive profile shows high dominance will report significantly lower cooperation than those groups with a leader whose motive profile shows low dominance.

In addition, the subordinates will be asked to rate their leaders using three subscales of the Leader Behavior Description Questionnaire (LBDQ) (Stodgill, 1974). The Integration subscale measures the leader's behavior to help the group work cooperatively; the communication subscale measures the behavior of the leader to provide means for communication; the Dominance subscale measures the amount of authority the leader exerts over the group (and the reverse is the amount of participation in decisions the leader allows). For each of the three subscales it is hypothesized that there will be a positive correlation between group member reports of cooperative leader behavior and group member judgements of cooperation.

Finally, the subjects will be asked to report their feelings about how well their group has accomplished its goals. Staw (1975) and Mitchell (1977) have questioned the validity of self-report measures because of the possible attributional bias of respondents. They contend that subjects attribute "causes" of performance according to their own personal theories of behavior. This has been tested, and results showed subjects attributing one set of 
characteristics to high performing groups and another set to low performing groups when all information on the two groups was identical except for the knowledge of the group's performance (Staw, 1975). Mitchell et al. (1977) found that perceptions of good performance subsequently resulted in higher ratings on leader behavior and job characteristics. Both of these studies explain these correlations by stating that subjects have their own hypotheses about behavior and attribute "causes" to the group's functioning based on their perception of group performance, and that these attributions may therefore confound the correlational results.

There has been considerable debate over the extent of attributional bias. This study cannot resolve the debate but it can identify the possibility of attributional bias in cooperation research. It is hypothesized that individuals' ratings of satisfaction wtih group performance will correlate significantly with their ratings of satisfaction with group cooperation, group atmosphere, and leader behavior. 


\title{
CHAPTER II
}

\author{
METHOD
}

SUBJECTS

Employees of Tektronix, an electronics firm in Wilsonville, Oregon, served as subjects. Many employees at Tektronix work in groups of three to twenty members to set and achieve group work goals. One member is designated as manager or supervisor. This work environment provided a population of groups of subjects with interdependent goals, the criterion for cooperation or competition described by Deutsch (1949a).

Existing work groups, contacted through the Human Resources Department, were given a brief description of the study and asked to participate. Fifteen existing work groups, a total of 129 subjects, volunteered to complete the questionnaire. The subject population was made up of 53 females and 73 males (three did not specify sex). Ten of the 15 group leaders were male, 5 were female. The ages of the subjects ranged from 20 to 58 , with a mean of 35.52 . Subjects reported a mean of 2.70 years of experience with current group and 2.24 years of experience with current leader. 


\section{INSTRUMENT}

The Appendix contains the final version of the instrument. The questionnaire was a 55-item scale with a 5point Likert response scale ranging from "never" to "always." The questionnaire was developed by compiling relevant scale or subscale items from the following instruments:

- The Manifest Needs Questionnaire (Steers \& Braunstein, 1976) is a 20-item instrument designed to measure Achievement, Affiliation, Dominance and Autonomy needs. The scale is behaviorally based using specific references to the workplace. Each of the four motive subscales is made up of five items, one or two of which are reverse coded.

The development and validation of this instrument involved management students, white-collar employees, and hospital employees as subjects (Steers \& Braunstein, 1976). Internal reliability is reported as alpha coefficients: Achievement $(\mathrm{ACH}), 0.66$; Affiliation $(\mathrm{AFF}), 0.56$; Dominance (DOM), 0.61; Autonomy (AUT), 0.83. Test-retest reliability was reported as $0.72,0.75,0.77$, and 0.86 , respectively. This same study reported correlations (ACH, 0.61; AFF, 0.40; DOM, 0.42; AUT, 0.62) with corresponding measures on the Personality Research Form (Jackson, 1967). 
- Tjosvold's (1984) Scale was used to measure cooperative or competitive orientations. This 19-item scale was developed to measure these constructs using behaviorally-based items. The items were generated using Deutsch's (1949a) theory of cooperation and competition. Factor analysis of preliminary data collected from medical technicians resulted in two factors, one with seven items measuring cooperation and one with seven items measuring competition. Cronbach alpha coefficients are reported as 0.91 for cooperation and 0.90 for competition subscales. The intercorrelation for cooperation and competition is reported as $\mathbf{- 0 . 6 2}$. There are no other published uses of this scale, probably due to its recent development. Eight items drawn from the 14-item scale were used in this study, 4 measuring cooperation and 4 measuring competition.

- The Leader Member Relations Scale (Fiedler, 1978) is a widely used scale and was developed to measure group atmosphere and the extent to which a leader and his or her subordinates are friendly and cooperative. This scale is the latest measure of group atmosphere used in Fielder's Contingency Theory of Leadership (1978). This scale was administered in two forms: leaders responded to items referring to themselves and relations with their subordinates (e.g., "I can trust and rely on the members of my work group"), and group members responded to the items 
referring to themselves and their supervisor le.g., "MY supervisor can trust and rely on the members of my work group"). All eight items on the IMR were used in this study.

- The Leader Behavior Description Questionnaire (Stodgill, 1974) and the Leader Opinion Questionnaire (Stodgill, 1974) both provided items which were used to measure leader behavior. The Leader Behavior Description Questionnaire ( $L B D Q)$ is an accepted measure of leader behavior as described by subordinates. The Leader Opinion Questionnaire (LOQ) is essentially the same instrument, phrased so that leaders describe their own behavior. Items were drawn from the Integration, Communication, and Dominance subscales. A total of 16 items from the LBDQ were used for the subordinates' questionnaire and a total of sixteen items describing similar behaviors to those on the LBDQ subscale were selected from the LOQ and used for the supervisor questionnaire.

Three items describing work satisfaction were specifically developed for this study. The items were modeled after standard measures of satisfaction found in the literature. The following three items were used:

1. "How satisfied are you with your performance over the past six months?" 
2. "How satisfied are you with your group's performance over the past six months?"

3. "Overall, how satisfied are you with your job right now?"

Subjects responded by indicating whether they were "very," "somewhat," or "not at all" satisfied.

The questionnaire made up of the above items was administered to several individuals to refine readability and item comprehension.

\section{PROCEDURE}

Subjects were administered the questionnaire by the researcher at their workplace during a weekly staff meeting of each work group. The questionnaire required 20 to 30 minutes to complete. Supervisors and subordinates received appropriately phrased versions of the questionnaire. Subjects were assured of anonymity and confidentiality verbally, again on an informed consent form, and on the questionnaire.

The first page of the questionnaire provided complete instructions and assurances of anonymity. Each of the five sections was preceded by brief instructions identifying the referent for the subject (e.g., "The following items describe individuals; please describe yourself").

Each subject was given a packet that consisted of two informed consent forms and the appropriately phrased 
questionnaire. Attached to the packet was a card with a fourdigit identification number that corresponded to a number on the questionnaire. The identification number was described as a device to identify the group.

Subjects were assured that the information would not affect their job in any way and would be completely confidential and anonymous and that the data would only be reported as group averages. Subjects were asked to answer all items honestly and completely. The researcher then answered any questions the subjects had prior to completing the questionnaire.

After completing the questionnaire, subjects were given a brief verbal description of the hypotheses and their importance. All questions and comments were answered. Subjects were asked to retain the identification card so that they could receive confidential personalized feedback on their responses to the Manifest Needs Questionnaire. Feedback was given in person by the researcher one to two weeks later. Each subject received a sealed envelope labeled with the identification number. The envelope contained a graph profiling the individual's score on each of the need scales and a sheet explaining each of the four scores. A brief verbal description of the need scales and their relation to work styles was presented. All questions and comments were answered. 


\section{CHAPTER II I}

\section{RESULTS}

\section{RELIABILITY OF MEASURES}

To determine internal reliabilities, Cronbach's Alpha and subscale correlations were calculated for each scale. Tjosvold's Cooperation scale is described in Table I. The

\section{TABLE I}

COOPERATION SCALE CHARACTERISTICS

TOTAL

SCALE

COOPERATION COMPETITION

Number of Items

8

31.11

4.25

.74

Alpha

Correlations:

Total Scale

Cooperation
Competition

Cooperation
Competition
4

14.95

2.62

.76
.64

4

16.11

2.58

$\begin{array}{lll}- & .81 * & -.81 * \\ - & - & -.34 * \\ - & - & -\end{array}$

$p<.001$ 
reliabilities for the cooperation, competition, and summed items are adequate. Table I also shows the subscale correlations. The negative correlations between the cooperation and competition subscales were expected due to the reciprocal nature of the items' phrasings.

The internal reliability of the LBDQ subscale was adequate (see Table II). As expected, the Integration and

\section{TABLE I I}

LEADER BEHAVIOR DESCRIPTION QUESTIONNAIRE SUBSCALE CHARACTERISTICS

\begin{tabular}{lccc}
\hline & INTEGRATION & COMMUNICATION & DOMINANCE \\
\hline Number of Items & 4 & 4 & 6 \\
Mean & 16.55 & 11.43 & 15.80 \\
SD & 2.59 & 2.11 & .78 \\
AIpha & .65 & .73 & $-.49 *$ \\
Correlations: & - & $.55 *$ & $-.54 *$ \\
Integration & - & - & -
\end{tabular}


Communication scales correlated positively with each other $(r(120)=.55, p<.001)$, and each correlated negatively with the Dominance scale.

The LMR scale, used to measure the extent to which groups were friendly and cooperative with their leader also showed adequate reliability (see Table III). The scale mean

TABLE III

LEADER MEMBER RELATIONS SCALE CHARACTERISTICS

\begin{tabular}{lc}
\hline & $\begin{array}{c}\text { Leader Member } \\
\text { Relations }\end{array}$ \\
\hline \# of Items & 8 \\
Mean & 30.78 \\
SD & 3.68 \\
Alpha & .76 \\
Correlations & $.55 *$ \\
$\quad$ Cooperation & $-.49 *$ \\
$\quad$ Competition & \\
\hline$\quad p<.001$ & \\
\hline
\end{tabular}

was 30.78, and the alpha coefficient was .76 . There was a significant positive relationship between the LMR and cooperation and a significant negative relationship between the LMR and competition. 
The alpha coefficients and intercorrelation matrix for the Manifest Needs Questionnaire subscales are presented in Table 4. The reliabilities for the Achievement,

TABLE IV

MANIFEST NEEDS QUESTIONNAIRE SCALE CHARACTERISTICS

\begin{tabular}{|c|c|c|c|c|}
\hline & ACH IEVEMENT & AFFILIATION & AUTONOMY & DOMINANCE \\
\hline \# of Items & 5 & 5 & 5 & 5 \\
\hline Mean & 19.27 & 15.66 & 13.88 & 16.23 \\
\hline$S D$ & 2.29 & 2.77 & 2.41 & 3.33 \\
\hline Alpha & .40 & .32 & .37 & .70 \\
\hline \multicolumn{5}{|l|}{ Correlations } \\
\hline $\mathrm{ACH}$ & $x$ & -.01 & .00 & $.33 * *$ \\
\hline $\mathrm{AFF}$ & - & - & $-.38 * *$ & -0.01 \\
\hline AUT & - & - & - & $.24 *$ \\
\hline DOM & - & - & - & - \\
\hline$\star p<.01$ & & & & \\
\hline$\star * \quad p<.001$ & & & & \\
\hline
\end{tabular}

Affiliation and Autonomy scales fall far below those reported by Steers \& Braunstein (1976) which ranged from 0.56 to 0.83 . Only the Dominance subscale showed acceptable 
reliability $(.70)$. The intercorrelations between the need scales were as expected. The Dominance scale correlated positively with the Achievement scale, indicating a relationship between the need for Dominance and the need for Achievement. The Dominance scale also correlated weakly with the Autonomy scale. The negative correlation between Affiliation and Autonomy is consistent with McClellend's (1961, 1965) original definitions of the two concepts. These intercorrelations may be explained, at least in part, by the small sample size drawn from a narrowly-defined population (i.e., office staff personnel working in the electronics industry).

\section{TEST OF HYPOTHESES}

To test the four hypotheses concerning the effect of leader motivation on group cooperation, high and low leader motive groups were determined by a median split of the group leader's score on each of the four motive scales. The means for the cooperation items and competition items for both high and low groups in each of the four motives are presented in Table $\mathrm{V}$.

The Dominance motive showed significant differences between high and low groups on the Cooperation scale, $t=3.18, p<.002$, and on the competition items, $t=3.62$, $r<.001$. There were no significant differences in 
TABLE V

GROUP MEMBERS' PERCEFTIONS OF COOPERATION AND COMPETITION WHEN GROUP LEADERS' MOTIVES ARE COMPARED

$\begin{array}{cc} & \# \text { OF } \\ \text { MOTIVE } & \text { GROUPS }\end{array}$

GROUPS

COOPERATION

COMPETITION*

Affiliation

$\begin{array}{llllll}\text { Low } & 6 & 14.70 & (\mathrm{n}=51) & 16.00 & (\mathrm{n}=52) \\ \text { High } & 9 & 14.78 & (\mathrm{n}=61) & 16.91 & (\mathrm{n}=61)\end{array}$

Achievement

$\begin{array}{llllll}\text { Low } & 7 & 15.08 & (n=58) & 16.40 & (n=59) \\ \text { High } & 8 & 14.38 & (n=54) & 15.77 & (n=54)\end{array}$

Autonomy

$\begin{array}{llllll}\text { Low } & 7 & 14.43 & (n=46) & 16.34 & (n=47) \\ \text { High } & 8 & 14.96 & (n=66) & 15.93 & (n=66)\end{array}$

Dominance

$\begin{array}{llllll}\text { Low } & 6 & 15.35 & (n=34) & 17.20 & (n=34) \\ \text { High } & 9 & 14.48 & (n=78) & 15.63 & (n=79)\end{array}$

* Lower scores on this scale indicate perceptions of greater competition existing within the group.

cooperation measures on the Affiliation, Achievement, or Autonomy motives.

One-way ANOVAS were calculated on each of the four hypotheses testing the effect of leader motivation on group cooperation. Results supported the hypothesis that leaders with high Dominance motivation would have groups that 
reported less cooperation than groups with low Dominance motivated leaders, $F(1)=7.291, p<.01$ (see Table VI). Groups with high Dominance leaders reported significantly lower cooperation than groups with low Dominance leaders. Achievement, Affiliation, and Autonomy motivation of leaders had no effect on levels of cooperation in the work groups. One-way ANOVAS for each proved nonsignificant.

\section{TABLE VI}

SIGNIFICANT DIFFERENCES IN COOPERATION AND COMPETITION BETWEEN GROUPS LED BY INDIVIDUALS OE HIGH AND LOW NEED FOR DOMINANCE

\begin{tabular}{|c|c|c|c|c|c|c|}
\hline $\begin{array}{l}\text { DEPENDENT } \\
\text { VARIABLE }\end{array}$ & $\begin{array}{l}\text { LEADER } \\
\text { MOTIVE }\end{array}$ & df & & $\mathrm{ms}$ & $F$ & $\mathrm{p}$ \\
\hline Cooperation & Dominance & 1,122 & $\begin{array}{l}\text { explained } \\
\text { residual }\end{array}$ & $\begin{aligned} 1 & =125.79 \\
& =17.25\end{aligned}$ & 7.29 & $<.008$ \\
\hline Competition & Dominance & 1,122 & $\begin{array}{l}\text { explained } \\
\text { residual }\end{array}$ & $\begin{aligned} & =52.28 \\
& =6.47\end{aligned}$ & 8.11 & $<.005$ \\
\hline
\end{tabular}

To test the hypothesis that there would be a positive correlation between group member reports of cooperative leader behavior and group member judgements of cooperation, correlation coefficients were calculated. Cooperation correlated positively with leader communication behavior $(r=.48)$, negatively with leader dominance behavior $(r=-.37)$, and had no significant relationship with leader integration behavior. 
Table VII presents correlation coefficients for satisfaction with performance, group atmosphere, cooperation, and leader behavior. Satisfaction with the work group is significantly correlated with cooperation $(r=.36)$, group atmosphere $(r=.49)$, and leader's communication behavior $(r=.41)$. Job satisfaction correlates significantly with only one outcome, group cooperation. Satisfaction with one's own efforts shows only weak or nonsignificant correlation. 


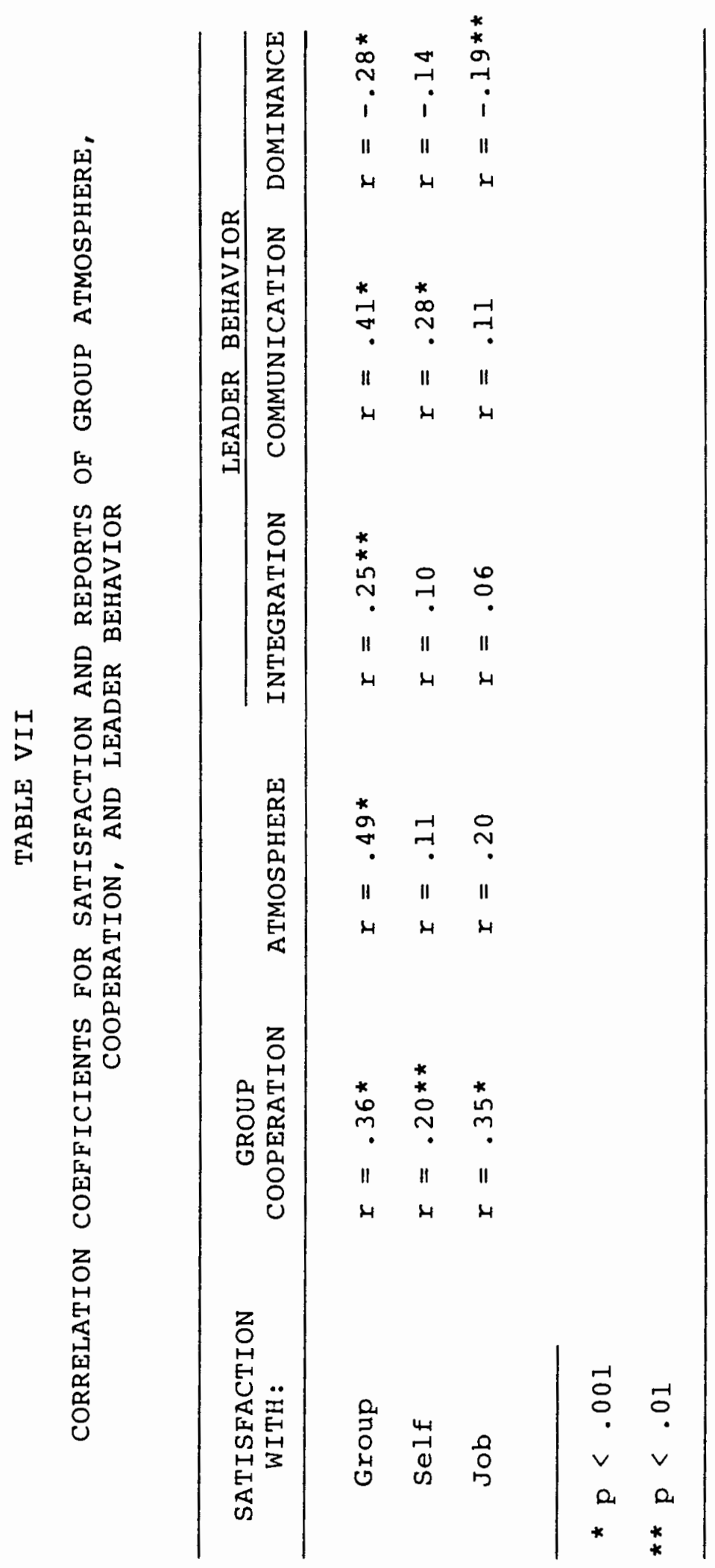


CHAPTER IV

\section{DISCUSSION}

This study demonstrates that Dominance (DOM) motivation of the leader can be used to predict the level of cooperation in work groups. The hypothesis that groups with leaders whose motive profiles show high DOM will report less cooperation than those groups with leaders whose motive profiles show low DOM was supported. Leaders with high DOM motivation will produce groups low in cooperation. This effect can be explained by examining the interaction between Deutsch's Theory of Cooperation and Competition $(1949 a, b)$ and Path Goal Theory of Leadership (Evans, 1970; House, 1971).

Path Goal Theory states that the leader clarifies the path to goals for his or her subordinates. In groups (such as the groups in this study) with a common interdependent goal, the leader can structure the path to the goal as either cooperative or competitive. Kelley \& Thibaut (1969) defined cooperative and competitive goal structures in terms of rewards. Cooperative structures base rewards on the quality of group efforts, and competitive structures make rewards scarce: one member earns maximum rewards, and other members earn minimum rewards. 
In defining the path to the goal as cooperative or competitive, the leader can use formal or informal rewards. Praise, recognition and monetary rewards are all powerful and dependent on availability. Even in an organization which values cooperation and distributes organizational rewards based on group performance, the leader can define rewards within the group as either cooperative or competitive.

The competitive goal structure in groups with high DOMmotivated leaders is due to the incompatibility of cooperation and the need for DOM. The DOM-motivated individual is motivated by a need to avoid the influence of others, to be in a position of authority over others, to control information, resources and the activities of others, and to influence the behavior and attitudes of others. In short, the high DOM-motivated individual has a need for power over people and situations. The need for dominance and power is not met by the processes and outcomes of cooperation as described by Deutsch $(1949 a, b)$.

Each of the four processes and outcomes of cooperation result in a sharing of power by the group. The first outcome, Expected and Actual Assistance, involves a sharing of information and resources among group members. This decreases the control and power of the leader. The processes and outcomes of Task orientation, Communication and Influence, 
and Friendliness and support also serve to enhance cohesiveness and distribute power and influence throughout the group.

Given these processes and outcomes of cooperation, it is not surprising that high DOM-motivated leaders would initiate competitive goal structures within their groups. A competitive goal structure prevents the cohesive processes and outcomes of cooperation, thus increasing group dependence on the leader. The leader then controls information, resources, activities, and influence within the group.

It is important to note that this effect was significant in a highly cooperative sample. The groups in this study reported moderate to high levels of cooperation. The mean response on the competition items was approximately 2.0 (on a 1-5 Likert scale, with 1 representing "never" and 5 representing "always"), indicating very low competition in this sample. This is probably due to the method of obtaining groups for participation. A list of supervisors who might agree to participate was obtained from the Human Resources Department. Group leaders were then contacted by the researcher and asked to participate. It must be assumed that the list included only those group leaders who had a history of cooperating with such requests. This selection method, and the fact that Tektronix, Inc., as an 
organization, values the team concept and participative management, served to skew the sample to cooperation. It would be expected that with a larger, random sample, the negative effect of a high DOM-motivated leader on group cooperation would be more pronounced.

The ideal sample would be a comprehensive testing of all groups in an organization such as Tektronix, Inc. and in a more traditional organization that does not promote cooperation. In this way, both the effects of dominance and the effect of organizational climate on cooperation could be examined. To do this, organizations must be convinced of the advantage of investing time and subsequently money into such research projects. Preliminary studies such as this one begin to lay the groundwork for large-scale field studies in cooperation research.

The effect of a high DoM-motivated leader is clear, but this study failed to demonstrate a causal relationship between leader Affiliation (AFF), Achievement (ACH) or Autonomy (AUT) motives and cooperation. It was hypothesized that groups with leaders whose motive profiles show high AFF would report higher cooperation than those groups with leaders whose motive profile shows low AFF motivation. There was no support for this hypothesis. This was also the case for the hypothesis that groups with high $\mathrm{ACH}$ leaders would report higher competition than groups with low $\mathrm{ACH}$ 
leaders and the hypothesis that groups with high AUT leaders would report lower cooperation than groups with low AUT leaders.

The test of these hypotheses is confounded by the poor reliability of the scale used to measure these leader motives, the Manifest Needs Questionniare. The reliabilities of the $A F F, A U T$, and $A C H$ subscales were far below those reported in previous research (S.teers \& Braunstein, 1976). The DOM subscale did reach previously reported levels of acceptable reliability. Considering the acceptable reliability of the DOM subscale and the good reliability of the other measures used in this study, the poor reliability appears to lie in the three subscales of the Manifest Needs Questionnaire itself rather than in poor presentation of the scale. The scale was presented third among four scales using the same 5 -point response scale throughout the questionnaire.

Due to the inadequate reliability, the data concerning a causal relationship between leader $\mathrm{ACH}, \mathrm{AFF}$, or AUT motives and group cooperation are inconclusive. The confirmation of the effect of DOM motivation on cooperation signals that the other three motives might play a role in group cooperation. It may be possible to test for this effect by using different measurement techniques such as the TAT (MCClelland and Boyatris, 1982). The TAT is a popular method of measuring 
motives, but as a projective method it presents reliability problems of its own. Considerable training would be required to interpret motives from subject responses to the TAT. In addition, the amount of time required from the subject might be prohibitive to the participating organization. This is always a major consideration when conducting field studies in a corporate setting. The development of a reliable and efficient measure of motivation is needed to further investigate the relationship between leader motive and cooperation.

In contrast to the Manifest Needs Questionnaire, this study supports the use of self-report measures of cooperation. Tjsovold's (1984) scale was successfully modified to apply to intragroup cooperation. The reliability of this scale was good despite the reduced number of items (8) and the small sample size (15 groups, 127 total subjects). The confirmation of reliability of the Tjosvold scale is important because there are no published uses of the scale other than those by Tjsovold. The reliability achieved here gives strong support to Tisovold's previous research using this scale.

This study modified the scale to provide a measure of intragroup cooperation. There is very little literature exploring intragroup cooperation. This scale provides a tool for exploring intragroup cooperation as a dependent 
variable. This will allow researchers to isolate variables that might cause intragroup cooperation and competition so that after considering both interpersonal and productivity consequences, groups can be designed to function cooperatively or competitively. This study, exploring the effects of leader motivation on group cooperation, is a step in that direction.

The importance of Tjsovold's scale as a tool for field study must be mentioned. There is debate over generalizing the results of laboratory studies to field settings. This debate is especially heated when the laboratory studies use college students as subjects. Gordon, Slade \& Schmitt (1986) analyzed 32 studies that involved both student and nonstudent subjects under identical research conditions and found significant differences between the two subject groups. They argue that research utilizing only students as subjects is inadequate as conclusive research. They conclude that more field studies are needed to clarify the application of laboratory results to field settings.

The need for more field studies is especially true in the area of cooperation research. Cooperation and competition involve considerable interpersonal consequences, the extent of which often cannot be duplicated in a lab. For example, the interpersonal relationships, both personal and professional, of ongoing work relationships are 
impossible to simulate in a laboratory. The field setting provides the opportunity to investigate cooperation and competition in the context of ongoing relationships and work-related goals. Tjsovold's scale is an economical, efficient, and reliable tool to measure cooperation in field settings.

The positive relationship between Tjsovold's scale and the Leader Member Relations (LMR) scale (Fiedler, 1978) supports the use of the IMR as a measure of cooperation. The LMR, commonly used as a measure of group atmosphere, can also be used to measure group cooperation. This will allow users of the LMR to describe the measure as at least partially due to group cohesion and cooperation.

Before further discussion of the present research findings, the issue of attributional bias in self-report measures must be addressed. Staw (1975) and Mitchel1 (1977) contend that subjects will attribute "causes" to group function based on group performance. In this study, the positive correlations between satisfaction with group performance and cooperation, group atmosphere, and leader communication behavior may be in part due to attributional bias. Group members may have attributed good group performance to cooperation, group atmosphere, and/or leader behavior. Subject attributions cannot be controlled and therefore must be taken into consideration when interpreting 
data derived through self-report.

Previous research has addressed the role of cooperation in satisfaction with one's task in laboratory studies (Deutsch, 1949b; Haines \& McKeachie, 1967) and in field settings (Blau, 1954; Tjsovold, 1986) and has found job satisfaction to increase with cooperation. These correlations support the above studies; however, they cannot refute the attributional bias reported by Staw (1975) and Mitchell (1977). Further research must resolve this debate.

There was no relationship between satisfaction with one's own performance and cooperation, but there was a slight negative correlation with competition. It is proposed that individuals lack techniques to assess their own performance under cooperative conditions. Individuals are conditioned to compete from birth, and self-evaluation is tied to competition. Group members may not have developed methods of assessing their own performance in the context of group rewards. This issue merits further study to determine whether individuals do assess performance differently in cooperative and competitive situations and, if warranted, the development of techniques for individuals to assess their own performance.

The final set of correlations to be discussed deals with the hypothesis that a positive correlation exists between group member reports of cooperative leader behavior 
and group member judgements of cooperation. Two leader behaviors were measured to test this hypothesis, providing means for group members to communicate, and integrative behaviors. As expected, leader efforts to provide means for group communication were positively related to cooperation. The leader that provides the means for communication may also be providing the means for cooperation. Combining Cooperation Theory (Deutsch, 1949b) and Path Goal Theory (House \& Mitchel1, 1974), the leader is providing means to communicate, a path necessary for cooperation.

The second leader behavior, integrative behavior, was not related to cooperation. At first glance this is surprising, but when Path Goal Theory is applied, the results are clearer. Although the leader is charged with providing and clarifying paths to goals, House \& Mitchell (1974) caution the leader to avoid redundancy. They found that subordinates become dissatisfied when the leader supplies redundant information. Integrative behavior may have been viewed as redundant in this study due to the integrative practices of Tektronix, Inc. In terms of cooperation, the actual behavior of the leader does not seem as important as the climate the leader influences.

Although it is not possible to make sweeping conclusions about the effect of leader motivation on group cooperation, the results of this study are encouraging. The 
negative effect of leader DOM motivation on group cooperation establishes a causal link between leader motivation and cooperation. The question of the effects of $A C H, A F F$, and $A U T$ motivation remains unanswered until a reliable method of measuring these motives is developed, but it is strongly suspected that these motives will also affect group cooperation.

The processes and outcomes of cooperation have been established as positive and desirable for organizations (Deutsch, 1949; Tjsovold, 1984, 1986) concerned with both production and the quality of work life for their members. As the causes of group cooperation are isolated, it will be possible for organizations to design cooperating groups. This study has demonstrated that if cooperation is the goal, leaders with high DOM motivation should be avoided. In addition, leaders should be trained to encourage communication and provide an atmosphere that allows group members to interact with one another.

The data in this study should be considered preliminary because they are the first to examine the effect of leader motivation on cooperation. Further study utilizing larger, random samples is in order to clarify the results. In addition, other methods assessing both motivation and cooperation are needed; field observation of interaction content and patterns and the critical incident interview 
technique are just two methods that might be employed. 


\section{REFERENCES}

Blau, P. M. (1954). Cooperation and competition in a bureaucracy. American Journal of Sociology, 59, 530535 .

Deutsch, M. (1949a). A theory of cooperation and competition. Human Relations, 2, 129-152. Deutsch, M. (1949b). An experimental study of the effects of cooperation and competition upon group process. Human Relations, 2, 199-231.

Deutsch, M. (1980). Over fifty years of conflict research. In Four decades of social psychology. New York: Oxford University Press, 46-77.

Dunn, R. E. \& Goldman, M. (1966). Competition and noncompetition in relationship to satisfaction and feelings toward own-group and nongroup members. Journal of Social Psychology, 68, 299-311.

Evans, M. G. (1970). The effects of supervisory behavior on the path-goal relationship. Organizational Behavior and Human Performance, 모 277-298.

Fiedler, F. E. (1978). The contingency model and the dynamics of the leader process. Advances in Experimental Social Psychology, 11, 59-112. 
Gordon, M., Slade, L. E., \& Schmitt, N. (1986). The "Science of the Sophomore" revisited: From conjecture to empiricism. Academy of Management Review, 11, 191-207.

Haines, D. B. \& McKeachie, W. J. (1967). Cooperative versus competitive discussion methods in teaching introductory pychology. Journal of Educational Psychology, 58, 386390 .

Harkins, S. G. \& Petty, R. E. (1982). Effect of task difficulty and task uniqueness on social loafing. Journal of Personality and Social Psychology, 43, 12141229 .

House, R. J. (1971). A path-goal theory of leadership effectiveness. Administrative Science Quarterly, 16, $321-338$.

House, R. J. \& Mitchell, T. R. (1974). Path-goal theory of leadership. Journal of Contemporary Business, $3,31-$ 99.

Jackson, D. N. (1967). Personality research form manual.

New York: Academic Press.

Johnson, D. W. \& Johnson, S. (1972). The effects of attitude similarity, expectation of goal facilitation, and actual goal facilitation on interpersonal attraction. Journal of Experimental Social Psychology, 8, $197-206$. 
Johnson, D. W. \& Johnson, R. T. (1974). Instructional goal structure: Cooperation, competitive, or individualistic. Review of Educational Research, 44 , 213-240.

Johnson, D. W., Maruyama, G., Johnson, R., Nelson, D., \& Skon, L. (1981). The effects of cooperative, competitive, and individualistic goal structures on achievement: A meta-analysis. Psychological Bulletin, $89,47-62$.

Johnson, S. \& Johnson, D. W. (1972). The effects of other's actions, attitude similarity, and race on attraction towards others. Human Relations, 25, 121-130. Jones, S. C. \& Vroom, V. H. (1964). Division of labor and performance under cooperative and competitive conditions. Journal of Abnormal and Social Psychology, $\underline{68}, 313-320$.

Kelly, H. H, \& Thibaut, J.W. (1969). Group problem solving. In G. Lindzay \& E. Aronson (Eds.), Handbook of Social Psychology, 4, 1-101.

Latane, B., Williams, K., \& Harkins, S. (1979). Many hands make light work: The causes and consequences of social loafing. Journal of Personality and Social Psychology, 37, $822-832$. 
Lewin, K., Lippett, R., \& White, R. (1939). Patterns of aggressive behavior in experimentally created social climates. Journal of Social Psychology, 10, 271-299. Mcclelland, D. C. (1961). The achieving society. Princeton: Van Nostrand Reinhold. McClelland, D. C. (1965). N-achievement and entrepreneurship: A longitudinal study. Journal of Personality and Social Psychology, 1, 389-392. McClelland, D. C. \& Boyatzis, R. E. (1982). Leadership motive pattern and long-term success in management. Journal of Applied Psychology, 67, 737-743.

Mitchell, T. R. (1979). Organizational behavior. Annual Review of Psychology, 30, 243-281.

Mitchell, T. R. (1977). Leader behavior, situational moderators, and group performance: An attributional analysis. Organizational Behavior and Human Performance, 18, 254-268.

Raven, B. H. \& Eachus, H. T. (1963). Cooperation and competition in means-interdependent triads. Journal of Abnormal and Social Psychology, 67, 307-316. Scott, W. E., Jr. \& Cherrington, D. J. (1974). Effects of competitive, cooperative and individualistic reinforcement contingencies. Journal of Personality and Social Psychology, 30, 748-758. 
Staw, B. M. (1975). Attribution of the "causes" of performance: A general alternative interpretation of cross-sectional research on organizations. Organizational Behavior and Human Performance, 13, 414432 .

Steers, R. M. \& Braunstein, D. N. (1976) . A behaviorallybased measure of manifest needs in work settings. Journal of Vocational Behavior, 9 , 251-266. Stodgill, R. M. (1974). Handbook of leadership: A survey of theory and research. New York: Free Press. Tjsovold, D. (1981). Unequal power relationships within a cooperative or competitive context. Journal of Applied Social Psychology, 11, 137-150.

Tjsovold, D. (1984). Cooperation theory and organizations. Human Relations, $37(9), 743-767$.

Tjsovold, D. (1986). Organizational test of goal linkage theory. Journal of Occupational Behaviour, 7, 77-88. Zander, A. \& Wolfe, D. (1964). Administrative rewards and coordination among committee members. Administrative Science Quarterly, $\underline{9}$, 50-69. 
APPENDIX

SAMPLE QUESTIONNAIRE PHRASED FOR LEADER 
Portland State UnIversity

Department of Psychology

As part of a Master's Thesis, I am conducting a study to examine some factors that effect cooperation in the workplace. As a volunteer in the study, you are asked to complete the following questionaire about your work group and supervisor. All of the information that you provide is confidential and will be seen only by the researchers. Your participation will not effect your job in any way.

There are no correct or incorrect answers to any of the 1tems. These are descriptive items that describe characteristics of individuals and groups. They do not judge whether the characteristic is desirable or undesirable.

I appreciate your assistance in completing this questionaire. Please consider each item carefully and do not hesitate to answer honestly. It is important that your responses reflect your view of your work group, your supervisor, and yourself. Thank you for your help.

The questions which follow make it possible to objectively describe certain characteristics of work exoups. The items simply describe characteristics of groups; they do not judge whether the characteristic is desirable or undesirable. Therefore, in no way are the questions considered to be a "test" elther of the group or the person answering the questions. We simply want an objective description of what the group is Iike. Please descrlbe how you percelve your work broup.

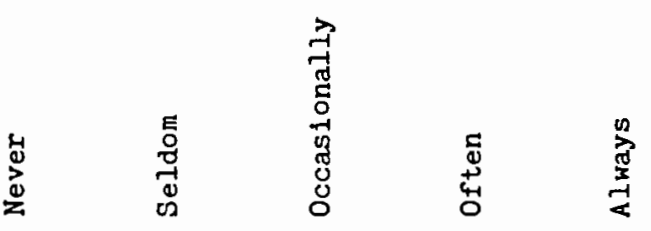

1. The members of my work group help me find ways to achieve my objectives.

1

2

3

5

2. The members of ny work group are threatened when I learn new skills and knowledge.

1

$$
2
$$

3

4

3. I learn a lot by working with my group members.

1

2

3

4

4. The members of my work group are threatened when I am highly effective. 
5. The members of my work group share their 1deas and resources with me.

6. The members of my work group restrict sor attempts for 1mprovement, they hold me back.

7. The members of my work group are pleased when I succeed.

8. The members of my work group like to show that they know more than I do.

9. The members of my work group have trouble getting along w1th each other.

10. Hy supervisor can trust and rely on the members of my work group.

11. There seems to be a friendly atmosphere among the members of my work group.

12. The members of my work group always cooperate with our supervisor in getting the job done.

13. There is friction and tension between the members of my work group and our supervisor.

14. The members of my work group give our supervisor a good deal of help and support in getting the job done.

15. The members of ny work group work well together in getting the job done. 
The following items describe individuais. Please describe yourself.

17. I do my best when job assigmments are fairly difficult.

18. When I have a choice I try to work in a group instead of by myself.

19. In work assigmments I try to be ry own boss.

20. I seek an active role in the leadership of a group.

21. I try very hard to 1mprove on my past performance at work.

22. I pay a good deal of attention to the feelings of others at work.

23. I go my own way at work, regardless of the opinion of others.

24. I avoid trying to Influence those around me to see things my way.

25. I take moderate risks and stick my neck out to get ahead at work.

26. I prefer to do my own work and let others do theirs.

27. I disregard rules and regulations that hamper ny personal freedom.

3

28. I find myself organizing and directing the work of others.

29. I try to avold any added responsibility on my job.

30. I express my disagreement with others openly.

31. I consider myself a "team player" at work. 
32. I strive for more control over the events around me.

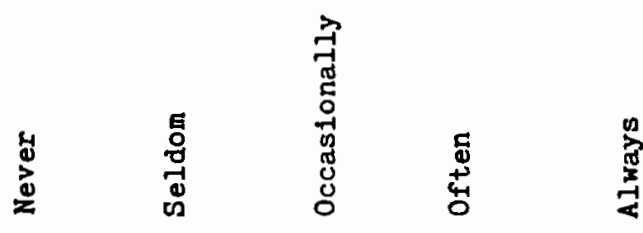

1

2

3

4

5

33. I try to perform better than my coworkers.

1

2

3

4

5

34. I find myself talking to my coworkers about non-business matters.

1

$\begin{array}{llll}2 & 3 & 4\end{array}$

35. I try my best to work alone on a job.

36. I strive to be "In command" when

$I$ an working in a group.

1

23

45

1

23

4

5

The following items make it possibe to describe certain chacteristics of leaders. Please describe your 1mmedlate suparvisor.

37. He or she refuses to compromise

a point

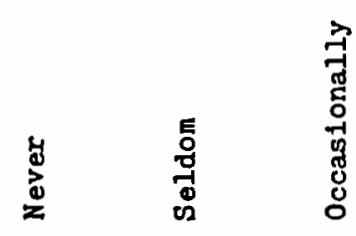

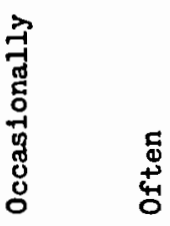

5

$* * * * * * * * *$

38. He or she discourages group members

from working as a team.

$$
1
$$

2

3

4

5

1

2

3

4

5

39. He or she calls the group together to talk things over.

1

2

3

4

5

40. He or she asks for sacrifices from individuals for the good of the group.

1

2

3

4

5

41. He or she insists everything be done his or her way.

3

4

5

42. He or she provides means for group members to communicate with each other.

1

2

3

4 

not to be questioned.
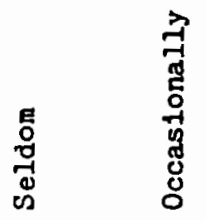

\section{He or she speaks in a manner}

44. He or she encourages understanding of points of view of others.

$$
1
$$

1

2

$$
3
$$

4

45. He or she lets the group set it's own goals.

1

2

3

5

46. He or she seeks information from group members.

1

2

3

5

47. He or she blames the same members when something goes wrong.

1

2345

48. He or she has group members share in making decisions.

345

49. He or she discourages members from expressing their ideas and opintons.

1

$\begin{array}{llll}2 & 3 & 4 & 5\end{array}$

50. He or she puts group welfare above the welfare of individuals.

1

2345

51. He or she pits one nember against another.

1

345

52. He or she gets group approval on 1 mportant matters before golng ahead

1

2

34

5

Please mark the response that best describes how satisfied you are.

53. How satisfied are you with your group's performance over the past 6 months?
Very
Somewhat
Not at all

54. How satisfled are you with your own performance over the past 6 months?
Very
Somewhat
Not at all

55. Overall, how satisfied are you with your job right now?

Very

Somewhat

Not at all 
How long have you worked for Tektronix?

How long have you worked in this group?

How long have you worked under this supervisor?

How long have you held your current position?

Are you female or male? (circle one)

Please state your age. 